\title{
Effects of age and gender on performance on Conners' Continuous Performance Test in Brazilian adolescents
}

\author{
Mônica C. Miranda, Thiago S. Rivero, and Orlando F. Amodeo Bueno \\ Universidade Federal de São Paulo, São Paulo, SP, Brazil
}

\begin{abstract}
The present study analyzed the effects of age and gender on performance on the Conners' Continuous Performance Test (CCPT II) in a sample of Brazilian adolescents aged 12-17 years. The sample consisted of 480 participants (210 boys) with a mean age of 14.34 years $(S D \pm 1.61$ years) who were representative of the socioeconomic class distribution of the city of São Paulo, Brazil. The participants were prescreened for attention-deficit/hyperactivity disorder. The present results found effects of age and gender that were similar to other Brazilian age groups. Compared with males, female participants presented a lower rate of responding to non-target stimuli (i.e., commission errors), a greater ability to discriminate signals (d'), and fewer impulsive responses (i.e., less perseveration) but longer reaction times (Hit RT and Hit RT Std Error). A significant effect of age was found on RTs (Hit RT, Hit RT Sdt Error, Variability, Hit RT Block Change), commission errors, and perseveration. As age increased, the differences diminished. The present results may be useful for research and clinical studies with Brazilian adolescents. Keywords: continuous performance test, adolescents, attention.
\end{abstract}

Received 17 August 2012; received in revised form 14 December 2013; accepted 20 December 2013. Available online 27 June 2013.

\section{Introduction}

Continuous performance tests (CPTs) are increasingly used to assess attentional processes such as sustained attention and as part of diagnostic tools for neurodevelopmental disorders such as attention-deficit/ hyperactivity disorder (ADHD). The most popular commercial continuous performance test is the Conners' Continuous Performance Test II (CCPT II; Conners, 2002), which consists of a computerized visual task that requires the subject to discriminate between target and non-target stimuli ( $\mathrm{X}$ and non- $\mathrm{X}$ letters). The individuals are instructed to press a computer key whenever any letter except X appears on the screen; therefore, the test requires an inhibitory response. The CCPT II provides 15 measures that potentially reflect different dimensions of attention, rather than only sustained attention, for which it was originally designed. A recent study of the construct validity of these measures by Egeland \& Kovalik-Gran (2010) found five different attention factors-focused attention, hyperactivity/impulsivity, sustained attention/vigilance, and control (change in control) - that help to differentiate clinical groups.

Mônica C. Miranda, Thiago S. Rivero, and Orlando F. Amodeo Bueno, Departamento de Psicobiologia da Universidade Federal de São Paulo, Associação Fundo de Incentivo a Pesquisa (AFIP), São Paulo, Brazil. Correspondence regarding this article should be directed to: Monica C. Miranda, R. Embaú 54, São Paulo, SP, 04039-060, Brazil. Phone: +55 (11) 5549-6899/5549-5496. Fax: +55 (11) 5572-5092; E-mail: mirandambr@yahoo.com.br
With regard to the effects of age and gender, studies have consistently shown that these factors are extremely significant in determining performance on several of the test's measures. Studies have found differences in various indices such as reaction time (RT), signal detection theory measures, and errors in school children (Greenberg \& Waldman, 1993; Lin, Hsiao, \& Chen, 1999; Conners, Epstein, Angold, and Klaric, 2003; Kanaka et al., 2008; Miranda, Sinnes, Pompéia, \& Bueno, 2008) and preschoolers (Kerns \& Rondeau, 1998; Conners, 2002; Miranda, Sinnes, Pompéia, \& Bueno, 2009).

A few studies have used this test in adolescents and adults. Conners et al. (2003) analyzed the CCPT II scores of participants aged 9-18 years and found that the adolescent group (14-18 years old) performed better than younger children on almost all measures, but smaller changes were found for the 14- to 15-yearold and older age groups. Hsieh et al. (2005) studied a larger sample of adults aged 21-50 years using a modified CPT-AX in which the participants must respond to an " $\mathrm{X}$ " if preceded by an "A" stimulus. They found effects of gender, age, and educational level only for Hit RT and detectability (d') scores. Burton et al. (2010) used the CCPT and found gender differences on measures of RT, commission errors, and d' and $\beta$ indices.

Markovska-Simoska \& Pop-Jordanova (2009) examined the influences of gender and age on a visual and emotional CPT task. No gender effects on task performance were observed, but age differences in omission errors were found on a visual CPT in the 31- 
to 40-year-old group compared with the 41- to 50-yearold group, and better performance was found on an emotional CPT in the young groups (18-20 and 21-30 years old).

Mani, Bedwell \& Miller (2005) conducted a study that assessed the influence of age in participants aged 19-84 years on performance on a modified version of the CPT and found that age was not associated with RT but increased false alarms and commission errors. Furthermore, inhibitory difficulties were more apparent in older individuals.

Few cross-cultural studies have compared CPT norms for different countries. The need for local norms is widely accepted because cultural factors may influence cognitive performance (Levav, Mirsky, French, \& Bartko, 1998). Children and adults from five cities (two in the United States, one in Canada, one in Ecuador, and one in Israel) were compared with regard to performance on the auditory and visual CPT-AX. The CPT results for children aged 8-12 years showed differences among cities only in commission errors on the visual task, whereas the 13- to 53-year-old age range showed differences in RTs on the auditory task.

Studies of a sample of Brazilian school children using the CCPT II (Miranda et al., 2008) and preschool children using the Conners' Kiddie CPT (K-CPT; Miranda et al., 2009) found effects of age and gender that were similar to those reported by other studies that used the CCPT II. However, when comparing the Brazilian and North American samples, Brazilian children showed better performance on most of the measures. The researchers concluded that these conflicting results may have reflected sample-selection differences, demonstrating the need for national performance parameters.

The present study analyzed a Brazilian sample aged 12-17 years using the CCPT II, which may be useful for research and clinical studies with Brazilians.

\section{Methods}

\section{Sample}

The sample selection procedures were the same as those used in previous studies of children (Miranda et al., 2008, 2009) who were recruited from public and private schools and reflected the socioeconomic class distribution on the Brazilian socioeconomic rating scale (http://www.abep.org; accessed May 26, 2013). After obtaining informed consent from the schools and parents, a health questionnaire was administered, and the following exclusion criteria were applied: signs of hyperactivity or inattention reflected by scores that were above the cut-off point for age and gender on the abbreviated Conners Rating Scale (Brito, 1987) and other developmental problems such as convulsions, diseases, and the use of medications. The final sample consisted of 480 participants aged 12-17 years.

The Ethics Committee of the Federal University of São Paulo approved this study.

\section{Statistical analysis}

The data were analyzed by age and gender using raw scores for each test variable. T-scores and percentiles were not analyzed because their values are converted from normative group values obtained in the United States (see Miranda et al., 2008 for a full description of all of the measures).

Normal distributions were tested using descriptive statistics (mean, median, skewness, and kurtosis coefficients), box-plots, and histograms. Normal distributions were found for two variables: \% commission errors and detectability.

Five variables (commission errors, Hit RT Block Change, Hit SE Block Change, Hit ISI Change, and Hit SE ISI Change) showed non-normality because of one or two discrepancies. After excluding these discrepancies, the distribution was approximately normal.

For the other variables, non-normality was caused by an asymmetric distribution. In these cases, we used logarithmic transformation $(\log [x+0.5]$ to avoid excluding zero values). Normality was reached after logarithmic transformation.

The effects of gender and age and interactions between these factors were analyzed using the General Linear Model, and the Bonferroni test was used to identify differences (Field, 2009). For the analysis of differences between age groups with regard to gender, the $\chi^{2}$ test was used. The data were analyzed using SPSS 13.0 software, and the significance level adopted was $5 \%(p<.05)$.

\section{Results}

The participants included 480 adolescents aged 12-17 years, with 210 boys and 270 girls (mean age, 14.34 years; $\mathrm{SD} \pm 1.61$ years). The proportions of boys and girls in the age groups differed only in the 13-yearold ( 40 boys and 60 girls), 14-year-old ( 47 boys and 61 girls), and 15 -year-old ( 26 boys and 39 girls) groups in which there were more girls $(p=.02)$.

No gender $\times$ age interaction was found for any of the CCPT measures $(p>.20)$. A significant effect of gender was found on the following measures: commission errors, \% commission errors, Hit RT, Hit RT Std Error, detectability, perseveration, and \% perseveration (Table 1). Female participants scored lower on commission errors and perseveration and higher on Hit RT and detectability (d').

Table 2 shows the means and standard deviations for the Brazilian adolescents' indices by age and gender. Effects of age were found, but significant differences were only found in commission errors, \% commission errors, Hit RT, Hit RT Sdt Error, variability, perseveration, \% perseveration, and Hit RT Block Change.

The analysis of commission errors and variability variables showed that the 12-year-old group only differed from the 17-year-old group $(p=.01)$. On the Hit RT Sdt Error measure, the 12- and 13-year-old groups differed from the 16-year-old group $(p<.03)$. 
Table 1. Gender and age effects on CCPT measures

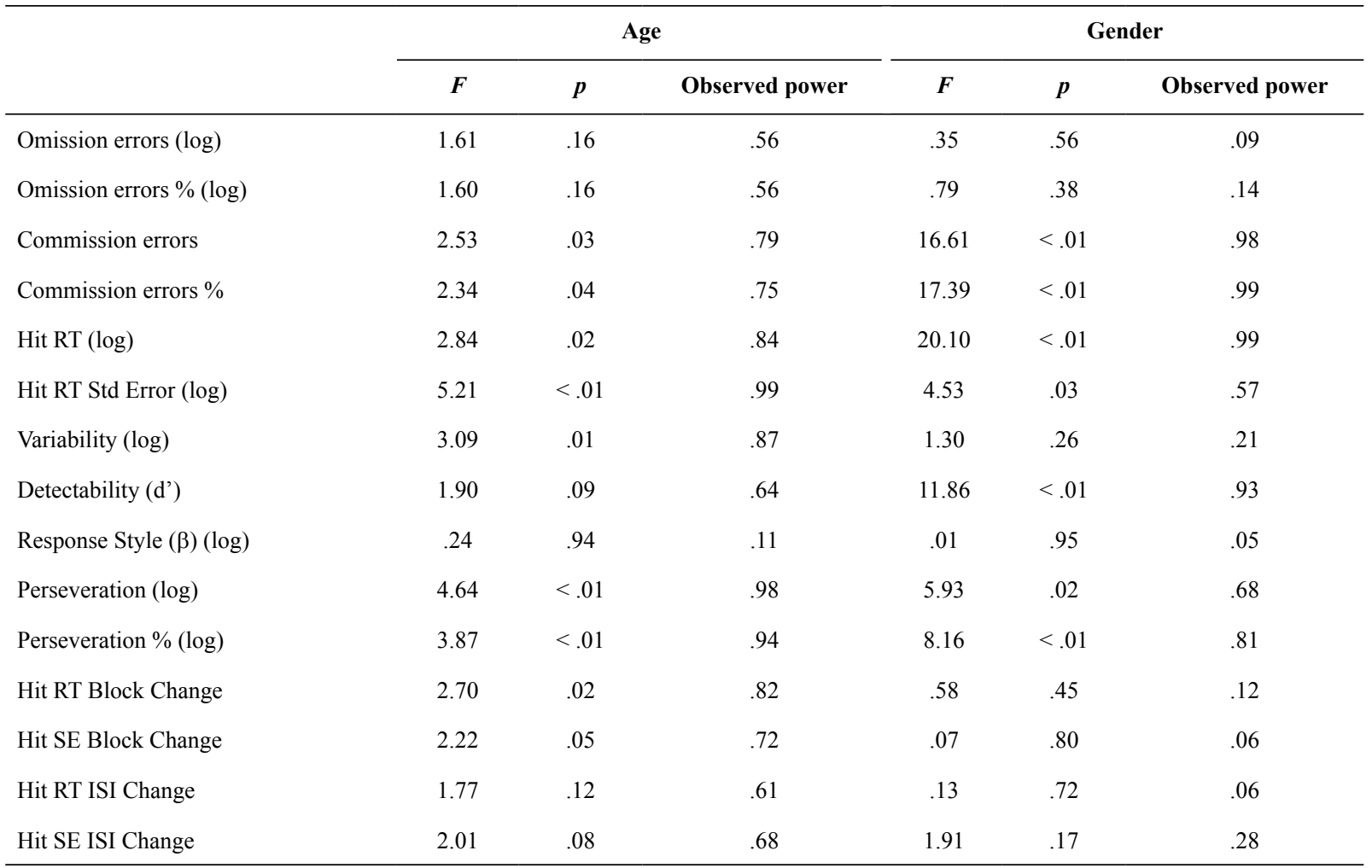

On the Hit RT Sdt Error measure, the 12-year-old group differed from the 15-, 16-, and 17-year-old groups ( $p$ $<.01$ ). For perseveration, significant differences were found between the 17-year-old group and the 12-, 13-, $14-$, and 16-year-old groups $(p<.05)$. No significant differences were found in the Hit RT Block Change measure between groups. Performance improved with age for all of the significant measures.

\section{Discussion}

The present data were similar to previous studies that used the same CCPT version for school-age children (Conners et al., 2003; Miranda et al., 2008) and preschoolers (Miranda et al., 2009) with regard to the absence of age and gender interactions. The present study found gender differences for only a few CCPT performance measures. Girls had a lower rate of responding to non-target stimuli (commission errors), a greater ability to discriminate signals (d'), and fewer impulsive responses (less perseveration) but a longer RT (Hit RT) compared with males. The present results are consistent with Burton et al. (2010) and similar to Hsieh et al. (2005) who studied adults and found gender effects only on measures of RT and the d' index; however, these previous studies used a different version of the CPT. A previous study of Brazilian school-age children (Miranda et al., 2008) also found gender differences in these measures, but more measures that differ by gender can be found with school-age children (i.e., the percentage of omission and commission errors, Hit RT, Hit RT Std error, and d' and $\beta$ indices).
Conners et al. (2003) also found gender differences on more measures, but their sample included children aged 9 years and older. The present study analyzed adolescents aged 12 years and older. Mani et al. (2005) did not make this comparison, which might best contribute to performance differences between genders in adolescents and adults. Nonetheless, our results showed that performance on CCPT measures may be less influenced by gender in older age groups.

The present study confirmed data from developmental studies of cognitive processes, which found that girls perform better in this age group. "Sex differences become more pronounced during the period of adolescence, concomitant with the hormonal changes of puberty, with females being more efficient than males in tasks of selective attention, verbal fluency and conductive reasoning" (Rubia, Hyde, Halari, GIampietro, \& Smith, 2010, p. 817). However, Burton et al. (2010) found relationships between personality factors and CPT variables in the male and female groups, especially in terms of response style and vigilance.

With regard to the effects of age in the present sample, comparisons between 12-year-olds and older adolescents revealed more numerous commission errors, greater variability, more frequent perseverative (anticipated) responses, slower RTs (Hit RT, Hit RT Sdt Error), and progressively slower RTs as the test progressed (Hit SE Block Change).

A study of school-age children (Miranda et al., 2008) found age differences for almost all of the CCPT II measures. Conners et al. (2003) found differences in more measures compared with the present study 


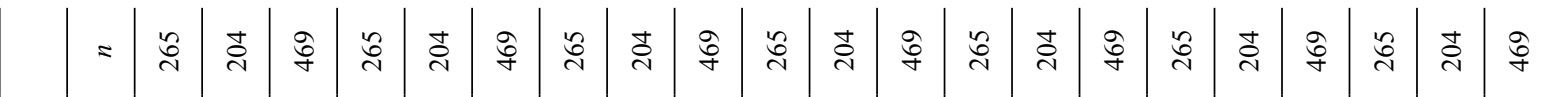

$$
\begin{aligned}
& \text { 密 } \\
& \text { 正 }
\end{aligned}
$$

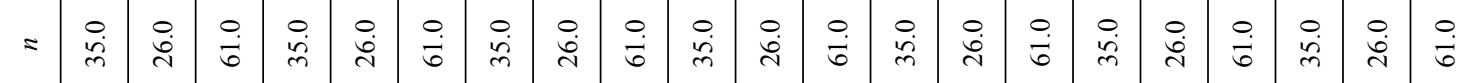

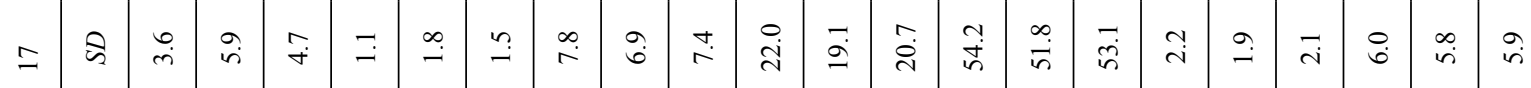

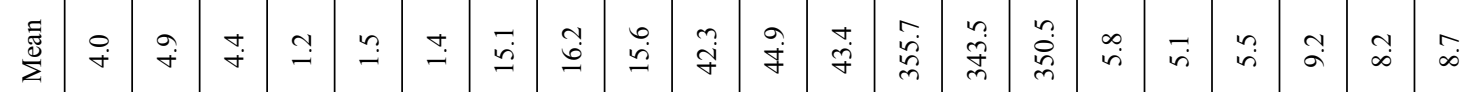

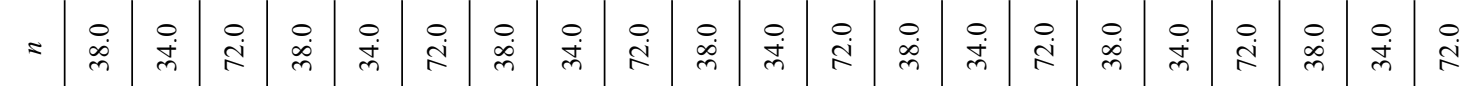

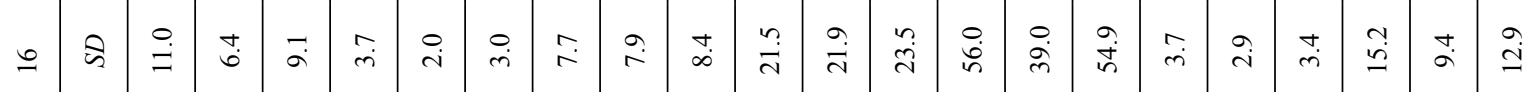

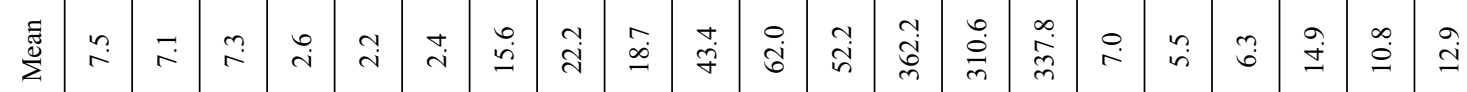

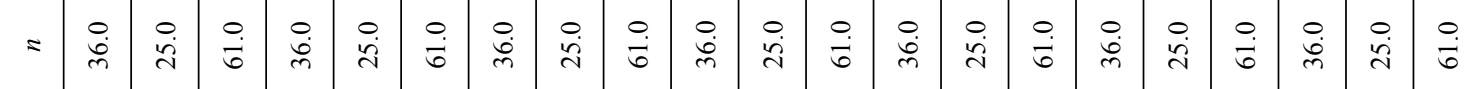

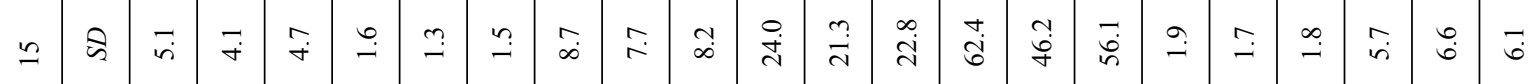

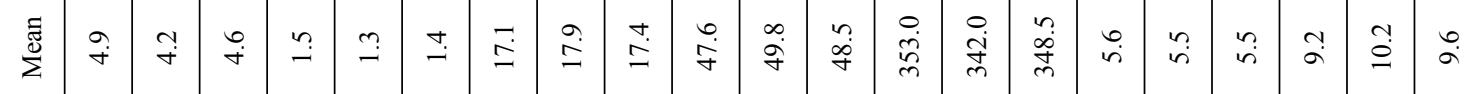

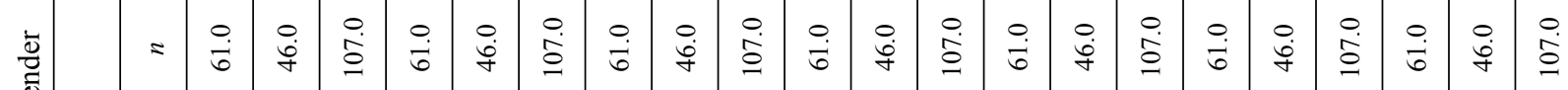

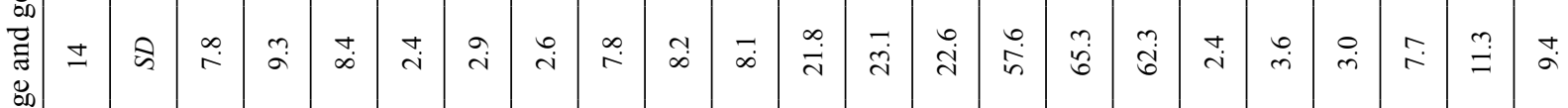

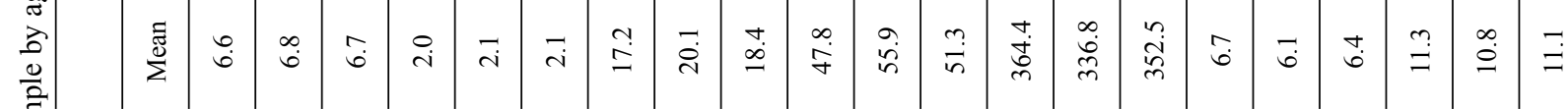

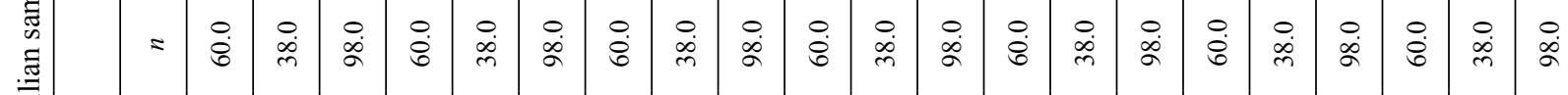

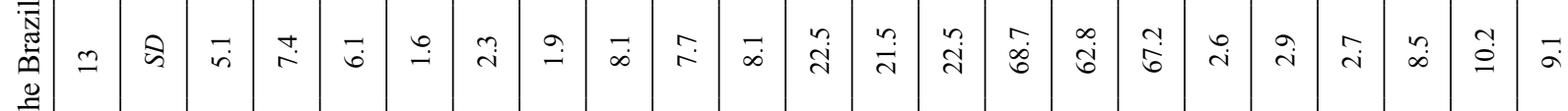

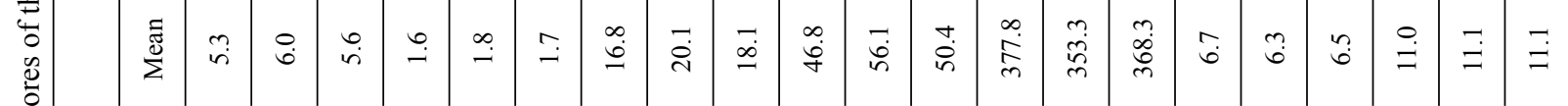

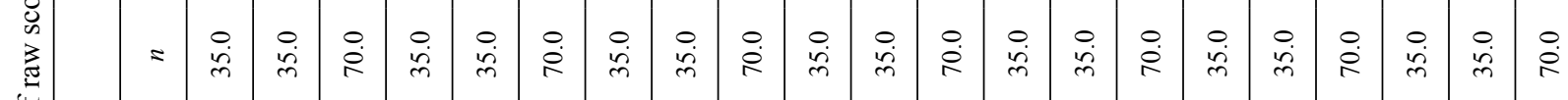
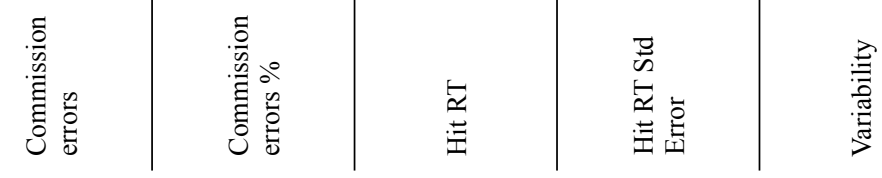


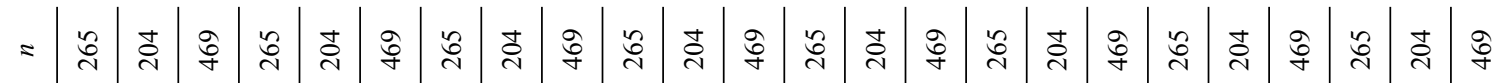

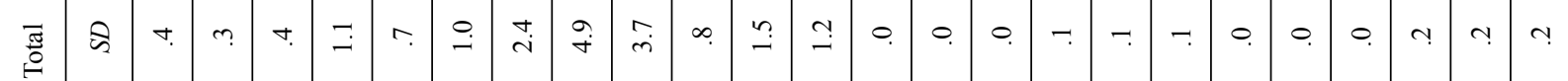

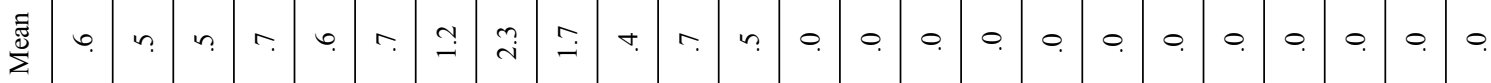

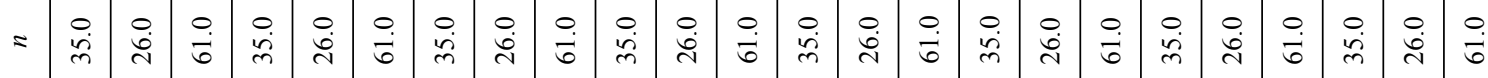

$$
\begin{aligned}
& \text { ป की ช. }
\end{aligned}
$$

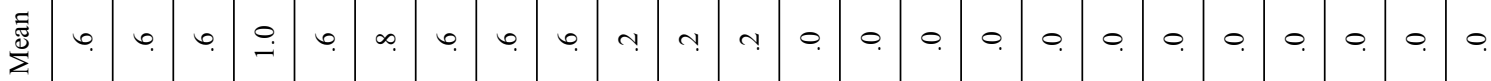

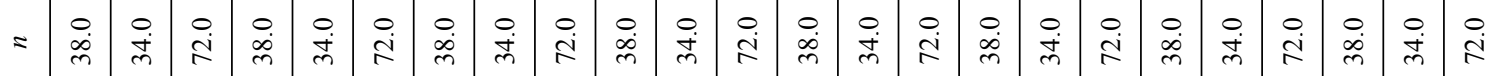

$$
\begin{aligned}
& \text { 으 }
\end{aligned}
$$

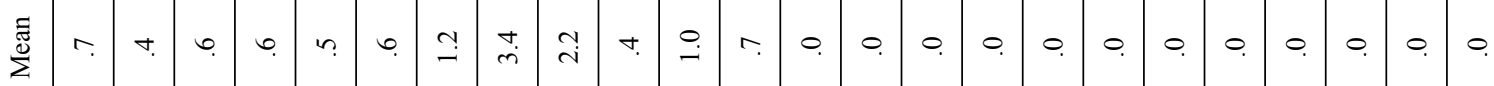

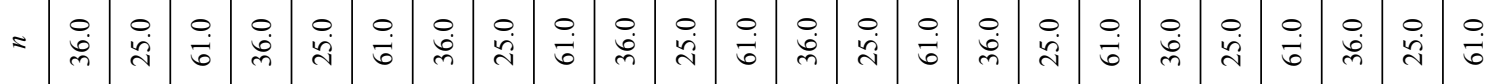

$$
\begin{aligned}
& \text { n } 2 \text { ค }
\end{aligned}
$$

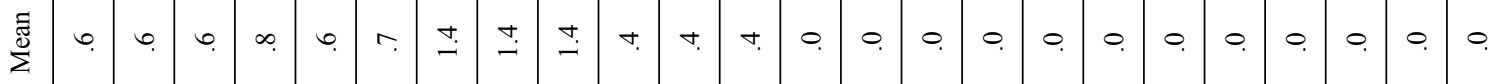

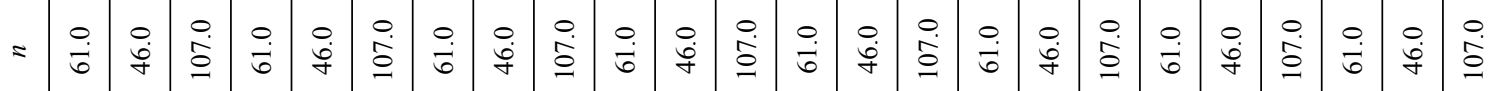

$$
\begin{aligned}
& \text { I }
\end{aligned}
$$

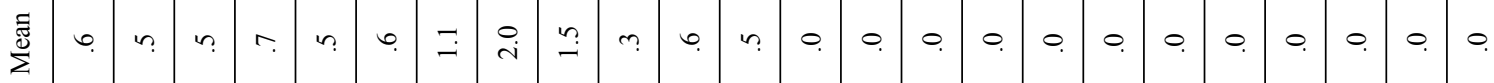

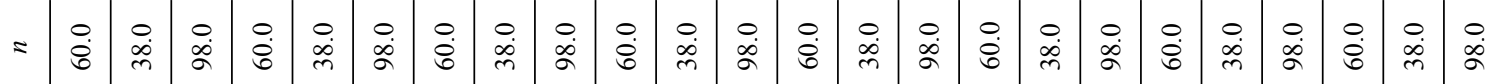

$$
\begin{aligned}
& m \text { के }
\end{aligned}
$$

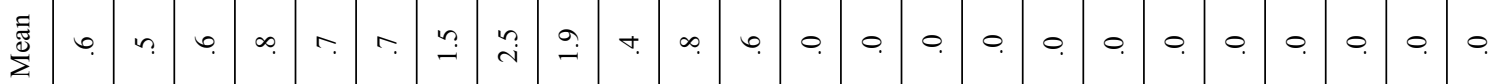

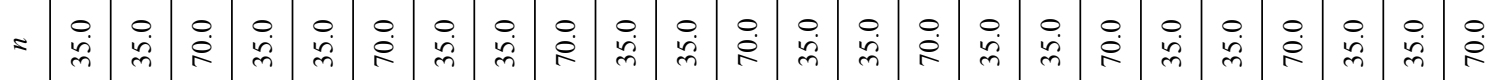

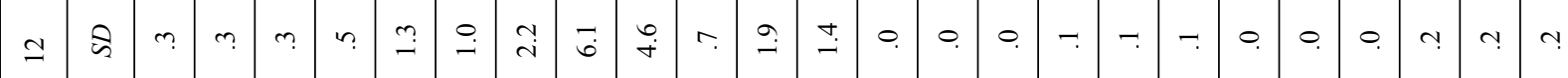

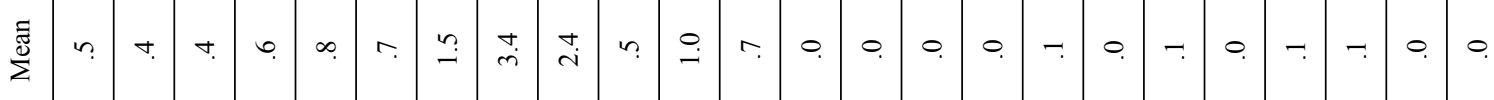

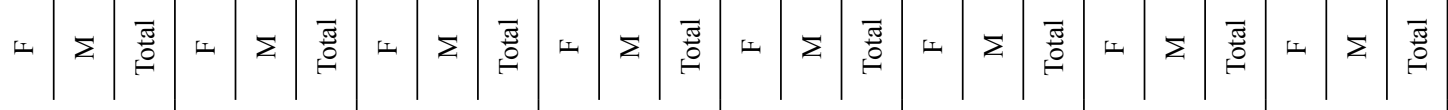

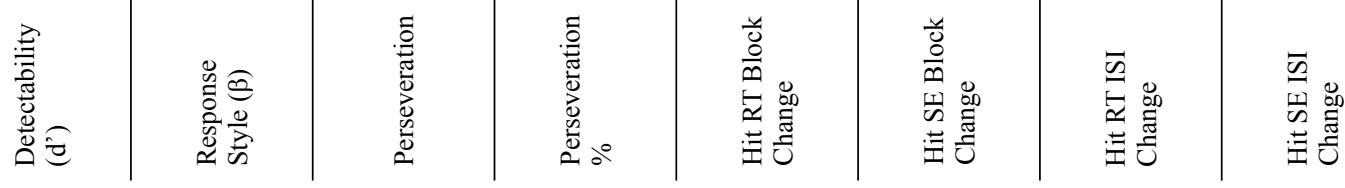


in which differences were found between the 12- to 13-year-old group and 16- to 18-year-old group on various measures including Hit RT, Hit RT Sdt error, omissions, commissions, $d$ ', and $\beta$. Comparisons of the 12- to 13-year-old group and 14- to 15-year-old group indicated that Hit RT was the only measure that was not different. Participants in the oldest age groups (14- to 15-year-olds and 16- to 18-year-olds) had shorter and less variable RTs, made fewer omission and commission errors, had an elevated d' index, and had a lower $\beta$ index than younger participants. Hsieh et al. (2005) used a different CPT version and found differences in fewer measures (i.e., only RT and d'). Mani et al. (2005) found that increasing age was associated with more numerous commission errors and false-alarms but not omission errors or RT and concluded that inhibitory difficulties were more apparent among older individuals.

This contrasts with the present findings in which younger participants had higher rates of commissions errors and perseveration (indicating impulsivity), more variability (a measure of "within-respondent" consistency), and a poor ability to sustain attention over time (Hit RT Block Change).

The discrepancies between the present findings and other studies cannot be attributed to different sample sizes because they were similar to the study by Conner et al. (2003). In any case, the differences found were similar in which performance improved with age, but this effect gradually diminished.

According to some developmental theories, the maturation of sustained and selective attention processes occurs during adolescence, a developmental period associated with behavioral and cognitive transitions (Smith, Halari, Giampietro, Brammer, \& Rubia, 2011), which may account for our finding that age-related differences diminished in the older groups, particularly with regard to impulsivity, for which we saw higher rates among the younger participants. Sergeant (2005) postulated that inhibition deficits may be attributable to energetic dysfunction, and poor response inhibition may be related to an effort/motivation effect. "Effort is defined as the energy necessary to meet task demands and affected by variables such as cognitive load and is required when the current state of the organism does not match that required to perform the task" (Sergeant, 2005, p. 1248)

Riccio, Reynolds, Lowe, \& Moore (2001) noted that CPTs may be viewed as measures of cognitive efficiency, which was corroborated by Smith et al. (2011) who compared commission errors between age groups and found linear increases with age that coincided with activation in brain regions typically associated with sustained attention, providing evidence for progressive age-correlated development from childhood through adulthood in task-relevant frontoparieto-temporal systems of cognitive control.

\section{Acknowledgements}

This study was financially supported by Fundação de Amparo a Pesquisa do Estado de São Paulo and Associação Fundo de Incentivo a Pesquisa.

\section{References}

Brito, G. N. (1987). The Conners Abbreviated Teacher Rating Scale: Development of norms in Brazil. Journal of Abnormal Child Psychology, 15, 511-518.

Burton, L., Pfaff, D., Bolt, N., Hadjikyriacou, D., Silton, N., Kilgallen, C., Cofer, J., \& Allimant, J. (2010). Effects of gender and personality on the Conners Continuous Performance Test. Journal of Clinical and Experimental Neuropsychology, 32, 66-70.

Conners, C. K. (2002). Conners' Continuous Performance Test. Toronto, Canada: Multi-Health System.

Conners, C. K., Epstein, J. N., Angold, A., \& Klaric, J. (2003). Continuous performance test performance in a normative epidemiological sample. Journal of Abnormal Child Psychology, $31,555-562$.

Egeland, J., \& Kovalik-Gran, I. (2010) Validity of the factor structure of Conners' CPT. Journal of Attentional Disorders, 13, 347-357.

Field, A. (2009). Descobrindo a estatística utilizando o SPSS. Rio Grande do Sul: Editora Artmed.

Greenberg, L. M., \& Waldman, I. D. (1993). Developmental normative data on the test of variables of attention (T.O.V.A.). Journal of Child Psychology and Psychiatry, 34, 1019-1030.

Hsieh, P. C., Chu, C. L., Yang, Y. K., Yang, Y. C., Yeh, T. L., Lee, I. H., $\&$ Chen, P. S. (2005). Norms of performance of sustained attention among a community sample: Continuous Performance Test study. Psychiatry Clinical Neuroscience, 59(2), 170-176.

Kanaka, N., Matsuda, T., Tomimoto, Y., Noda, Y., Matsushima, E., Matsuura, M., \& Kojima, T. (2008). Measurement of development of cognitive and attention functions in children using continuous performance test. Psychiatry Clinical Neuroscience, 62(2), 135-141.

Kerns, K. A., \& Rondeau, L. A. (1998). Development of a continuous performance test for preschool children. Journal of Attention Disorders, 2(4), 229-238.

Levav, M., Mirsky, A. F., French, L. M., \& Bartko, J. J. (1998). Multinational neuropsychological testing: performance of children and adults. Journal of Clinical and Experimental Neuropsychology, 20, 658-672.

Lin, C. C., Hsiao, C. K., \& Chen, W. J. (1999). Development of sustained attention assessed using the continuous performance test among children 6-15 years of age. Journal of Abnormal Child Psychology, 27, 403-412.

Mani, T. M., Bedwell, J. S., \& Miller, L. S. (2005). Age-related decrements in performance on a brief continuous performance test. Archives of Clinical Neuropsychology, 20(5), 575-586.

Markovska-Simoska, S., \& Pop-Jordanova, N. (2009) Comparison of visual and emotional continuous performance test related to sequence of presentation, gender and age. Prilozi, 30, 167-178.

Miranda, M. C, Sinnes, E. G., Pompéia, S., \& Bueno, O. F. A. (2008). A comparative study of performance on the Conners' Continuous Performance Test between Brazilian and North American children. Journal of Attention Disorders, 11(5), 588-598.

Miranda, M. C., Sinnes, E. G., Pompéia, S., \& Bueno, O. F. A. (2009). O K-CPT em uma amostra brasileira: Descrição do desempenho e comparação com as normas norte-americanas. Revista de Psiquiatria do Rio Grande do Sul, 31(1), 60-66.

Rubia, K., Hyde, Z., Halari, R., Giampietro, V., \& Smith, A. (2010). Effects of age and sex on developmental neural networks of visualspatial attention allocation. Neuroimage, 51(2), 817-827.

Riccio, C. A., Reynolds, C. R., Lowe, P., \& Moore, J. J. (2002). The continuous performance test: A window on the neural substrates for attention? Archives of Clinical Neuropsychology, 7(3), 235-272.

Sergeant, J. A. (2005). Modeling attention-deficit/hyperactivity disorder: a critical appraisal of the cognitive-energetic model. Biological Psychiatry, 57(11), 1248-1255.

Smith, A. B., Halari, R., Giampietro, V., Brammer, M., \& Rubia, K. (2011). Developmental effects of reward on sustained attention networks. Neuroimage, 56(3), 1693-1704. 